\title{
Life Sciences-Life Writing: PTSD as a Transdisciplinary Entity between Biomedical Explanation and Lived Experience
}

\author{
Norbert W. Paul ${ }^{1}$, Mita Banerjee ${ }^{2}$ and Thomas Efferth ${ }^{3, *}$ \\ Received: 7 July 2015; Accepted: 18 December 2015; Published: 30 December 2015 \\ Academic Editor: Albrecht Classen \\ 1 Institute for the History, Philosophy, and Ethics of Medicine, Johannes Gutenberg University Medical Center, \\ 55131 Mainz, Germany; norbert.paul@uni-mainz.de \\ 2 Institute of American Studies, Johannes Gutenberg University, 55099 Mainz, Germany; \\ mita.banerjee@uni-mainz.de \\ 3 Department of Pharmaceutical Biology, Institute of Pharmacy and Biochemistry, \\ Johannes Gutenberg University, Staudinger Weg 5, 55128 Mainz, Germany \\ * Correspondence: efferth@uni-mainz.de; Tel.: +49-6131-3925751; Fax: +49-6131-3923752
}

\begin{abstract}
Since the second half of the 20th century, the life sciences have become one of the dominant explanatory models for almost every aspect of human life. Hand in hand with biomedical developments and technologies, the life sciences are constantly shaping and reshaping human lives and changing human biographies in manifold ways. The orientation towards life sciences and biomedicine from the very beginning to the end of human life is driven by the utopian notion that all forms of contingency could be technologically and medically controlled. This paper addresses the interrelatedness of life sciences and human biographies in a field where contingency and risk become essential and existential parts of lived experience: post-traumatic stress disorder (PTSD). On the one hand, this diagnostic entity is related to (neuro-)biological underpinnings of (a lack of) psychic resilience as well as to those of contemporary pharmacotherapy. On the other hand, PTSD is also understood as based on a traumatic life event, which can be accessed through and addressed by talk therapy, particularly narrative exposure therapy (NET). We argue that a novel focus on concepts of narrativity will generate pathways for an interdisciplinary understanding of PTSD by linking biological underpinnings from neurobiological findings, to brain metabolism and pharmacotherapy via the interface of psychotherapy and the specific role of narratives to the lived experience of patients and vice versa. The goal of our study is to demonstrate why therapies such as psychotherapy or pharmacotherapy are successful in controlling the disease burden of PTSD to some extent, but the restitutio ad integrum, the reestablishing of the bodily and psychic integrity remains out of reach for most PTSD patients. As a test case, we discuss the complementary methods of Traditional Chinese Medicine (TCM) and the established procedures of talk therapy (NET) to show how a methodological focus on narratives enhanced by notions of narrativity from the humanities grants access to therapeutically meaningful, enriched notions of PTSD. We focus on TCM because trauma therapy has long since become an intrinsic part of this complementary medical concept which are more widely accessible and accepted than other complementary medical practices, such as Ayurveda or homeopathy. Looking at the individual that suffers from a traumatic life event and also acknowledging the contemporary concepts of resilience, transdisciplinary concepts become particularly relevant for the medical treatment of and social reintegration of patients such as war veterans. We emphasize the necessity of a new dialogue between the life sciences and the humanities by introducing the concepts of corporeality, capability and temporality as boundary objects crucial for both the biomedical explanation, the narrative understanding and the lived experience of trauma.
\end{abstract}


Keywords: life sciences; life writing; medical ethics; medical epistemology; narratives; pharmaceutical biology; posttraumatic stress disorder; war veterans

\section{What Is Life Writing and Why Should We Bother? Or: The Narrative Construction of Illness}

Life writing is not limited to memories of life recorded in the form of diaries and autobiographies. Beyond this narrative construction of autobiographical texts, forms of life writing can reach unprecedented degrees of authentic expression, if extreme, life-threatening situations of human life are being narrated, situations that often result in long-term traumata and mental impairment. Out of a plethora of documented illness narratives, the following three statements might provide a first impression of the relevance of life writing in this regard. In the internet blog "PTSD and Me: True Stories from Military Veterans", a US army veteran wrote: "In a poorly lit bunker that stunk of smoke, strong alcohol and vomit, that was something that one of hardened GI's said to me the first night I was deployed. It's stuck with me all these years, more years than you have probably been alive ... "Another soldier wrote: " . . my adrenaline rushes and I freak out, I'm afraid to have emotions, because I'm afraid of losing control ...." Depending on the severity of the disease, the symptoms persecute victims for the rest of their lives: “But today I couldn't escape what I had done more than 40 years ago. Although I came back, I've never escaped. And although I survived, how much of me died in the piece of shit swamp?" [1] These patients are going through crisis-ridden experiences in their lives. They suffer from a diagnosed disease termed posttraumatic stress disorder (PTSD) and, at the same time, from a biographical inscription of trauma. In this regard, the act of writing is both simple and complex. It is simple in the sense that for the patient, writing takes on a therapeutic function; it is a way of reflecting on, and making sense of, a mental impairment which challenges the individual's quality of life and his psycho-social well-being. While the mere act of writing is a form of introspection, the act of "blogging" connects him to others, who have found themselves in similar situations at the boundaries of human life, thus creating a sense of community through which individual experience can be transcended ${ }^{1}$. In this regard, the blog can be seen as a form of life writing [4-10]. While traditional research in autobiography has encompassed mostly written documents such as (literary) autobiographies or diaries, the current usage of "life writing" has modified this concept in multiple ways, considering new formats such as blogs, online videos, court testimonies and even non-verbal forms of representation. Life writing, as we use it here, has been particularly fruitful for interdisciplinary research. Forms of life writing can be understood as patient accounts. In trying to cope with experiences of illness or trauma, patients often turn to writing. This writing, in turn, provides medical practitioners with an in-depth view of the patient's own experience. Life-writing can thus function as an important link between a patient's experience and medical practitioners looking for forms of cure. Theorizing pathogenically relevant lived experiences, we argue, can be accomplished only through a dialogue, at the level of basic research, between life sciences and life writing, between medicine including psychiatry and the natural sciences on the one hand and the humanities on the other [7].

At this juncture, what is needed are new approaches to gaining access to conditions of human life. Here, the humanities may have had a blind spot in that they often fail to address the material dimension of the illness experience. In the humanities, the focus has often been on aspects of identity rather than the material reality of lived experience. Humanities research has mostly focused on the question how illness affects the identity of a given individual. However, such accounts can

1 The German term Grenzerfahrung which provides the basis for our research, cannot be easily translated into English. It is meant to convey experiences at the boundaries of human life, experiences which make us become aware of the most fundamental properties of human life, and the proposal of "life itself" [2]. On the concept of "zoe"(as being different from "blos"), cf. Rosi Braidotti, "Zur Disposition des Lebens im Zeitalter des genetischen Biokapitalismus", 2009 [3]. 
say little about the physicality of illness, let alone about diagnosis, treatment, and prognosis. It is at this point that a new transdisciplinary vision of lived experience creating a nexus between the humanities and the life sciences is needed. Through the field of life writing research, the humanities provide important insights into the way in which existential experiences are turned into narratives. Emotions of extreme happiness, of deep sorrow, guilt, fate, fight, dying and death are interpretative tools when it comes to the analysis of narratives. Not surprisingly, we often find cross-references to older, more philosophically inspired medical interpretations of human behavior like those of Karl Jaspers. However, the biological underpinnings of human behavior, be it the hormonal regulatory system, the neurological and neurobiological individuality or genetic variability (e.g., if it comes to concepts of resilience) has not been sufficiently integrated into humanities research. In the following, we will discuss pathways of a new dialogue between the life sciences, biomedicine and the humanities, using PTSD as a case in point.

\section{The Dialogue between Life Sciences and Life Writing: PTSD as a Case Point}

Frequently, the lived experience of a given crisis constitutes a starting point for processes that may have pathological value (anxiety), but which may also be a physiologically protective response (reactive depressive episodes). If the experience of crisis is highly challenging and professional help is not accessible, or if the latter is not successful, posttraumatic disorders may develop. In the field of life writing, trauma narratives have been among the most frequent genres to occur; these are narratives written, for instance, by the survivors of massacres, of natural catastrophes, or of human rights violations [8]. However, the humanities scholar will look in these narratives for signs and symptoms of the author's identity, as it is shaped, or rather, as it has been re-shaped by the experience of trauma. What happens, however, if the same text is interpreted by a humanities scholar and a practitioner from the medical field deeply rooted in the life sciences? It is this joint reading which we want to call for in this paper. The reflexive medical practitioner would "diagnose" in this text not the question of identity (the identity of a traumatized individual), but the physical and psychological effects of PTSD. First, he would distinguish between different kinds of responses to stress. Short-term anxiety is known as acute stress response. Anxiety persisting for longer times (more than one month) can develop into PTSD. This syndrome, which has been known as a medical phenomenon since World War I, was first labeled PTSD in the 1970s with regard to veterans of the Vietnam War. However, PTSD is not solely related to war, but also can occur after other severe traumata, include threat to death after criminal violence (sexual abuse, kidnapping), natural catastrophes (earthquakes), etc. Typical symptoms of PTSD are characterized by repeatedly experiencing the initial trauma by flashbacks, nightmares, and arousal (sleep disturbance, anger, hypervigilance). Frequently, PTSD leads to considerable impairments in the social life of patients. Liminal experiences such as PTSD are the object of several academic disciplines, including medicine, biology, psychology, literature, sociology, etc. (Figure 1, Table 1). 


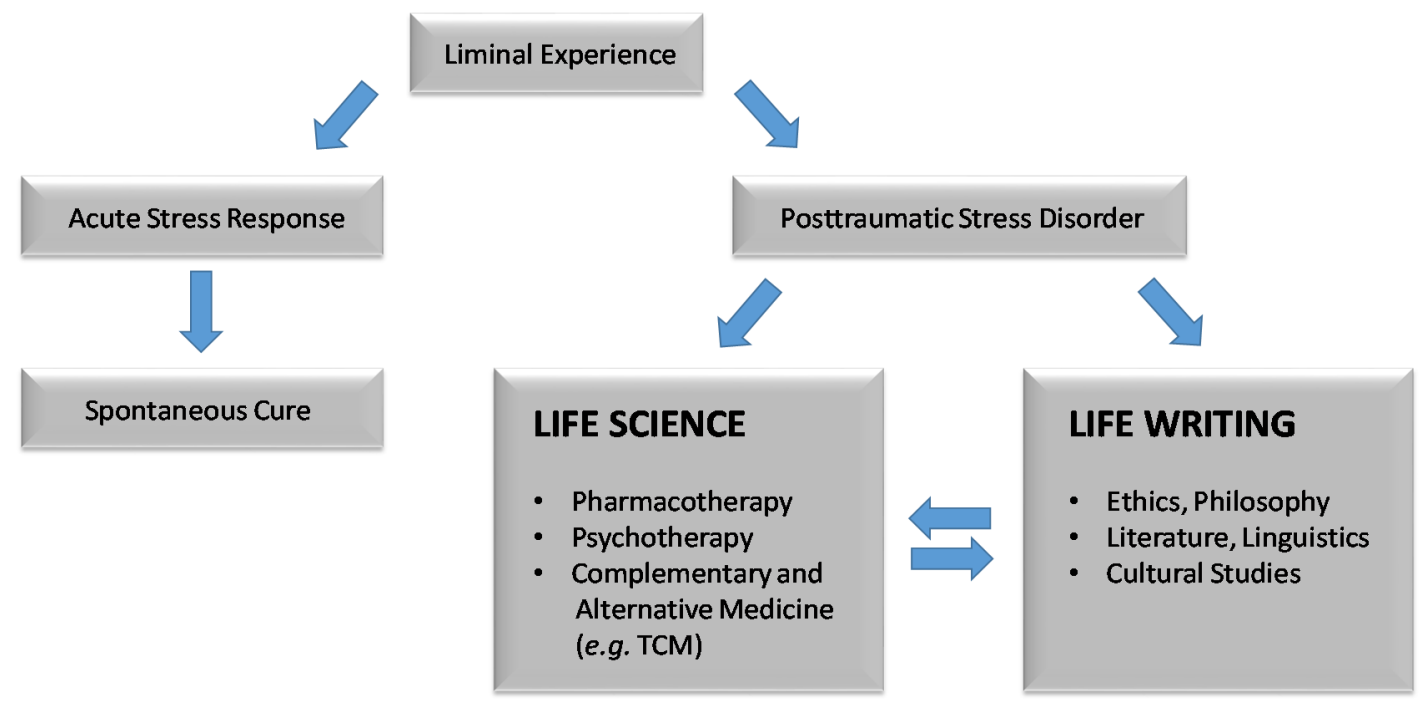

Figure 1. Liminal experiences in life as the basis of interdisciplinary research between different academic disciplines in life sciences and life writing.

Table 1. Transdisciplinary perspectives on narrative concepts of PTSD to avoid "blind spots".

\begin{tabular}{ccccc}
\hline Genre/field & Life sciences & Psychotherapy & TCM & Life writing \\
\hline Fiction as coping & not accessible & not accessible & not accessible & accessible \\
\hline Diaries, blogs & not accessible & not accessible & not accessible & accessible \\
\hline $\begin{array}{c}\text { Autobiography, biography } \\
\begin{array}{c}\text { Individual corporeality, capabilities } \\
\text { and temporalites }\end{array}\end{array}$ & not accessible & partly accessible & partly accessible & accessible \\
\hline $\begin{array}{c}\text { Therapeutic narratives to access } \\
\text { corporealities, capabilities and } \\
\text { temporalities }\end{array}$ & not accessible & partly accessible & partly accessible & partly accessible \\
\hline Therapeutic case reports & partly accessible & accessible & accessible & partly accessible \\
\hline Patient history in diagnostic findings & partly accessible & accessible & accessible & partly accessible \\
\hline Patient history in laboratory findings & accessible & accessible & partly accessible & not accessible \\
\hline Projection of patient prognosis & partly accessible & accessible & partly accessible & not accessible \\
\hline
\end{tabular}

However, genuine interdisciplinary collaborations aimed at combatting post-traumatic phenomena are in their beginnings, although there is a tremendous demand by persons affected as well as an enormous scientific innovation potential. To fully unfold interdisciplinary approaches, we need to first identify the linkages between the disciplines involved, and locate the precise points of intersection where the methodology of one discipline ends and is in need of being connected to the methodology of another. In exploring the continuum between PTSD in life writing and life sciences by means of life writing research, talk therapy, and traditional Chinese medicine (TCM), we will exemplify how PTSD can be understood as a boundary object in diverse methodological ontologies.

Most therapeutic approaches to PTSD have stressed talk therapy together with psychopharmacotherapy to enable the PTSD patient to deal with the most prevalent symptoms of PTSD: the loss of narrative coherence and the temporality of life, the reliving of the trauma, as if it was part of the present. The therapy hence aims at helping the patient regain narrative coherence and to create a "plausible" narrative of the traumatic event [9], also in order to regain the temporal structure of daily life as an indispensable precondition for anchoring coping processes. In this process, the traumatic event can be transferred into the intentional memory and can thus be inserted into the patient's self-narrative [9], from where it is accessible to further treatment and coping. The narrative through which the event is being reconstructed does not have to be "real" in its retelling of the actual 
occurrence; it only needs to construct a plausible "reality" in order to support autobiographical sense-making [9].

In the framework of talk therapy, supporting pharmacotherapy is now-after a period of methodological reluctance-playing an increasingly significant role, especially in the mastering of an acute aggravation of the disease. We propose that beyond established psychopharmacological regimens, the availability of effective medication for PTSD in TCM, pharmacotherapy together with complementary and alternative medicine may be used for the transgression of methodological orthodoxy in understanding and treating PTSD as a multifaceted boundary object in itself.

Significantly, in the overwhelming majority of accounts dealing with PTSD in life writing (autobiography, biographies, diaries) or in fiction and popular culture, there is little mention of methods other than talk therapy. Thus, there is a curious disconnect between narratives on the one hand and the availability of treatment methods through psychotropic pharmaceuticals on the other hand, nor is there an awareness, in these narratives, of alternative and complementary medicine such as TCM. As the above-mentioned chart indicates, searching for a nexus may be fruitful for both sides. So far, the field of life writing as it encompasses approaches from literature, linguistics, cultural studies, ethics, and philosophy, has focused on the idea of "crises of identity" in different narratives. We argue that, specifically in therapeutic contexts, we need to broaden our notion of narratives. Traditionally, narratives are connected to forms of fiction. However, diaries, blogs, autobiographic (unpublished) documents, biographical elements and even the body of the patient, the individual capabilities and challenges and accounts on subjective temporalities-such as the inconsistency of time in PTSD patients with so called flash-backs as contemporary lived experience-need to be understood as narratives in themselves. Especially, science and technologies studies showed during the last decades that therapeutic conversations and professional documentation down to laboratory sheets also can be analyzed as specific forms of narratives. Hence, the concept of trauma has been investigated in a number of different ways, yet humanities approaches have risked using this concept in its metaphorical sense only, disregarding the heterogeneity of the concept of trauma which in effect ranges from physiologically "normal" response to highly disabling psychiatric disease. In order to come to grips with this heterogeneity, we will take a closer look at therapeutic strategies-including $\mathrm{TCM}$ - and at approaches from the field of life writing and narrative theory.

\section{The Psychotherapeutic Dimension of PTSD}

Since 1980, when the American Psychiatric Association (APA) added posttraumatic stress disorder (PTSD) to the third edition of its Diagnostic and Statistical Manual of Mental Disorders (DSM-III), basic research and clinical practice have developed remarkably. Hand in hand with new explanatory models and the detection of pathogenic mechanisms and the behavioral and neurological underpinnings of PTSD, a number of different therapeutic strategies have evolved. From the beginning, the appreciation of the psychotherapeutic dimension of PTSD stimulated the search for effective and evidence-based interventions in order to provide treatment for those who were suffering from PTSD and/or trauma-related psychological problems.

As a result, a number of different psychotherapeutic interventions have been established [11,12]. What, at first sight, looks like therapeutic heterogeneity and a lack of evidence is much more likely an outcome of the need for situated and contextualized therapeutic strategies, especially if we take into account that trauma and therapeutic approaches to PTSD have to acknowledge the fact that patients are very different with regard to their culture, ethnicity, lived experience, social bonding and personal history. As a consequence, therapeutic interventions show a high degree of differentiation regarding the pattern of sessions and the exposure and stimuli used to target trauma [13]. Here, life writing narratives may in fact be an important complement since they express in detail the facets of an individual's identity. Regardless of the cultural or social differences between persons suffering from PTSD, however, it has recently been pointed out that "currently available empirically supported psychotherapies for trauma survivors have a lot in common" [11]: 


\section{Commonalities of therapeutic interventions for PTSD as described by Schnyder et al. [11]:}

- $\quad$ Psychoeducation offers information on the nature and course of posttraumatic stress reactions, identifies ways to cope with trauma reminders, and discusses strategies to manage distress. In trauma-focused psychotherapy, psychoeducation aims at facilitating interventions, optimizing patient cooperation, and preventing relapse.

- Emotion regulation and coping skills are frequently taught and trained across many therapeutic approaches. In some instances, this is done more implicitly, in others as an explicit element of the treatment.

- Imaginal exposure is strongly emphasized in PE (Prolonged Exposure Therapy, NWP) and NET (Narrative Exposure Therapy, NWP). However, some form of exposure to the patients' memory of their traumatic experiences can be found in virtually all evidence-based psychotherapies for trauma-related disorders.

- Cognitive processing, restructuring, and/or meaning making is another element that can be found in almost all of the empirically supported psychological treatments for PTSD. Although, in the cognitive approaches, these are the most important treatment components, in other protocols, they are conceptualized as part of the integration that takes place after or during exposure.

- Emotions are targeted in all psychotherapies. Some predominantly tackle the patients' trauma or fear network, others focus more or equally on guilt and shame, anger, or grief and sadness.

- Memory processes also play an important role in treating trauma-related disorders. No matter which technical terms are used, the reorganization of memory functions and the creation of a coherent trauma narrative appear to be central goals of all trauma-focused treatments.

Especially Narrative Exposure Therapy (NET) is deeply rooted in-partly implicit—concepts of narrativity [13]. This focus on narrative in its complex dimensions, in turn, is the core concern of humanities approaches, particularly in the areas of literary studies and life writing research. In light of the fact that PTSD patients are a particularly vulnerable group with reduced resilience with regard to new traumatic events, concepts of narrativity and narratibility, delineating the boundaries of what can be narrated and what cannot, need closer attention. This seems to be a pressing issue from our point of view, since narrativity-based exposure to the traumatic memory of patients is an integral part of almost every established evidence-based therapeutic intervention for PTSD. We argue that the treatment of PTSD should be embedded in a larger contexts of applied medical humanities to fully unfold the potential of concepts of narrativity and narratibility for a better understanding of the ways in which trauma can and cannot be narrated, and for comprehending the ways in which narration constitutes (new) meaning. Thus, within the field of the humanities, studies on the structure of narrative and on the process of narrativizing a traumatic event may fruitfully complement the above-mentioned therapeutic approaches. If therapeutic interventions have focused on the processing of memory, taking into account the narrative dimension of such processing may yield even more nuanced results, since it provides the therapist with an even more nuanced narrative and linguistic repertoire originating in literary and cultural studies.

\section{Pathophysiology and Pharmacotherapeutic Strategies}

The pathophysiology of PTSD has been intensively investigated during the past years. Brain areas responsible for the perception and the processing of emotional memories, e.g., prefrontal cortex, amygdala and hippocampus revealed characteristic changes compared to healthy subjects [14].

In addition to functional alterations, several biochemical reactions have been associated with PTSD. Stress reactions are regulated by the hormonal hypothalamic-pituitary-adrenal (HPA) axis, which is disrobed in PTSD patients. Hormonal disturbances include hypersensitive adrenaline responses, unbalanced urinary secretion of cortisol and catecholamine, decreased serotonin and dopamine levels in the brains and others [15].

Recently, units for genetic predisposition have been found, indicating that the susceptibility for PTSD after traumatic stress may differ between individuals. The human genome contains numerous small variations, which differ from population to population and from individual to individual. They are called single nucleotide polymorphisms (SNPs). While they do not lead to phenotypically 
relevant changes in functional alleles, SNPs are indicative for the metabolic variability also relevant for stress response. Well-known examples of metabolic variability are life-threatening toxicities resulting from medical drugs or the consumption of certain foods [16-18] correlating with certain SNP-patterns. Not surprisingly, SNPs in hormone-related genes have been associated with PTSD, e.g., in the genes encoding gamma-aminobutyric acid (GABA), catechole-O-methyl transferase (COMT), dopamine receptor, serotonin transporter (5-HTTLPR) and others [19,20].

It is striking that only a small number of individuals may develop PTSD, although traumatic experiences are quite frequent among the general population. This may indicate that several factors are likely to act in concert for the outbreak of PTSD. In addition to genetic causes, epigenetic factors may play a role, and both factors might be interconnected. It is only recently that the relevance of epigenetic mechanisms has been addressed as risk factors for PTSD as they can reflect both genetic and environmental influences [21-23]. While genetic changes focus on alterations in DNA, e.g., the substitution of a specific base pair by another one as it takes place in single nucleotide polymorphisms (SNPs), epigenetic changes are related to changes in DNA methylation, histone acetylation and microRNA activity. These epigenetic changes stably determine a cell's phenotype, but can affect dynamic adaptations of the brain to stressors in a quite flexible manner.

The limbic-hypothalamic-pituitary-adrenal axis (LHPA) is the primary regulatory circuit for stress response. Psychogenic stress factors such as severe traumata can lead to epigenetic changes of genes involved in LHPA axis causing both dynamic short-term changes, but it can also have long-term consequences [24]. Evidence has been found in the past few years, that epigenetics, and specifically DNA methylation, represents a factor for susceptibility to and the progression of PTSD. Epigenetic mechanisms allow cells to rapidly respond to environmental changes and challenges by regulating gene expression.

The epigenome is highly dynamic and can be modulated learning and memory processes, which are important in the context of PTSD. Early life events (e.g., traumas during childhood affect DNA methylation patterns and subsequent gene expression profiles. Aberrations in adaptive DNA methylation profiles may increase disease susceptibility, if an individual is not able to appropriately respond to environmental demands. Epigenetic mechanisms also contribute to higher order brain functions and, hence, aberrant methylation profiles are linked to neurodevelopmental and neurodegenerative cognitive disorders, affective disorders, addictive behavior, etc. [25].

There is a three-hit concept of vulnerability and resilience to stress-related mental disorders, which is based on gene-environment interactions during critical phases of perinatal and juvenile brain development. The three hits may be as follows: hit- 1 represents a genetic predisposition, hit- 2 comes from the early-life and hit- 3 from the later-life environment. This concept is based on the cumulative stress hypothesis stating that the vulnerability is enhancing, if an individual cannot cope with adverse events. The three hit concept also considers the individual's predictive adaptive capacity. The latter hypotheses propose that the experience of relatively mild early-life adversity prepares for the future and promotes resilience to similar challenges in later-life, i.e., if a mismatch occurs between early and later-life experience, an individual cannot cope with it and vulnerability is enhanced [26].

Here, we give only some examples on DNA methylation as epigenetic mechanism, since it has so far been most extensively studied for PTSD. Epigenetic investigations may serve as starting point to identify new targets for pharmaceutical and other treatments for PTSD [27].

Yehuda et al. [28,29] investigated cytosine methylation in the NR3C1-1F promoter of the glucocorticoid receptor gene in 122 combat veterans. Glucocorticoid receptors mediate a negative feedback of glucocorticoids (GC) in the paraventricular nucleus of the hypothalamus and anterior pituitary and therefore play a key role in the regulation of the HPA axis and the endocrine response to stress. The authors noted a lower NR3C1-1F promoter methylation status in combat veterans with PTSD as compared to combat-exposed veterans without PTSD. Furthermore, NR3C1-1F promoter methylation was inversely correlated with clinical markers and symptoms associated with PTSD. The authors concluded that NR3C1-1F promoter methylation may lead to functional neuroendocrine 
alterations. Early-life stress may cause epigenetic changes leading to long-lasting altered gene expression conferring an increased risk for PTSD development [30]. Methylation changes may not only last for decades in the same individual, but they may also be transmitted from generation to generation. Schafe $[31,32]$ reported on the transmission of PTSD to the offspring of mothers suffering from PTSD. Exposed mothers and their children had higher methylation of NR3C1 than non-exposed groups. Finally, exposed mothers showed higher methylation of CpGs located within the NR3C2 coding sequence than non-exposed mothers. Comparable results were described by Yehuda et al. [33] for FKBP5 methylation in holocaust survivors and their offspring. Hence, epigenetic modifications related to the HPA axis may be transmitted from mothers to children.

In addition to genes involved in the HPA axis, interleukins involved in immunological functions are also involved in PTSD-associated DNA methylation changes. Rusiecki et al. [34] found that the cytosine methylation of interleukins 8,16 and 18 was reduced in subjects without PTSD compared to PTSD patients. Additionally, pre-deployment the people who later became cases had lower levels of IL18\%5-mC compared with controls. Furthermore, Methylation changes were also observed in long-non-coding H19 sequences and LINE-1 repetitive DNA [35]. The relevance of these results remains to be further explored.

Epigenetic research may offers new opportunities to transcend the boundaries of psychiatry and open up avenues for interdisciplinary research. In contrast to genetics, epigenetics allows us to include environmental factors such as the social environment of an individual, which plays an important role for psychiatric disorders. Remarkably, the social environment may influence genes through epigenetic processes. Thus, epigenetic mechanisms might help explain how adverse social environments come "into the mind" and negatively affect mental health [36]. Low socioeconomic position (SEP) represents an example for this hypothesis. If SEP influences epigenetic patterns, SEP may enhance sensitivity to stress and, in turn, risk of PTSD [37].

PTSD is not a disease restricted to human beings. Thus, investigations on the PTSD-related epigenetic changes during the evolution of life on earth are possible on the basis of genome-wide bioinformatical comparisons. Sipahi et al. [38] analyzed PTSD-related CpG dinucleotides during the descent of humans in during mammalian evolution. They demonstrated that few (7\%) PTSD-associated CpG sites are unique to humans, while the vast majority of sites have deep evolutionary origins: $73 \%$ and $93 \%$ were unambiguously present in the last common ancestor of humans/orangutans and humans/chimpanzees, respectively. Genes proximal to evolved PTSD-associated CpG sites revealed significant enrichment for immune functions. It can be concluded that the human capacity to respond to trauma through stable physiologic and behavioral changes may be due to epigenetic potentials that are shared among many mammalian species.

In addition to psychological attempts to alleviate the symptoms of PTSD such as cognitive behavioral therapy to replace traumatic by less stressful thoughts, eye movement desensitization and reprocessing (EMDR), exposure therapy or stress inoculation training [39], pharmacological treatment can partially improve disease symptoms without satisfactory cure and is often used to control an acute (and severe) aggravation of the disease. Drugs showing varying treatment success are from diverse pharmacological classes, e.g., selective serotonin reuptake inhibitors, $\alpha$-adrenergic antagonists, anticonvulsants, mood stabilizers, antipsychotics, $\beta$-blockers, benzodiazepines, glucocorticoids, tricyclic antidepressants, and monoamine oxidase inhibitors [40,41].

\section{Treatment of PTSDS with Traditional Medicine}

As a matter of fact, psychotherapy and pharmacotherapy can reduce PTSD symptoms only to some extent and a sustainable cure still seems out of reach for many patients. Therefore, there is an urgent need for developing new treatment strategies. In this context, going beyond established strategies by looking at traditional phytotherapies with medicinal herbs and especially at TCM could offer new and effective treatment options. Anxiety and depression in general are symptoms that are probably as old as mankind. Therefore, it comes as no surprise that folk medicines all over the 
world have medicinal herbs in their repertoire for trauma treatment [42,43]. To name just a few, traditional European medicine offers St. John's Wort (Hypericum perforatum), containing hypericin and hyperforin as active principles, lavender oil (Lavandula angustifolia) with its essential oils and many others. Khat leaves (Catha edulia) are chewed in North Africa and Near East. They contain the alkaloid cathinone and are used as mood stimulant. The same is true for TCM with its 5000 year-old tradition. Although PTSD does not appear as an exactly defined disease in the old Chinese textbooks, the treatment of depression and anxiety is well known in TCM [44]. Recently, a pattern differentiation for PTSD has been identified using TCM diagnosis [45]. Famous herbal remedies contain plants such as Bupleurum chinense, Paeonia lactiflora, Silybum marianum, Rumex crispus, Polygonum multiflorum, Medico sativa, Angelica sinensis, etc.

Evidence for the activity of medicinal herbs from TCM came from a clinical trial on 245 survivors of the 2008 Sichuan earthquake suffering from PTSD [46]. This clinical trial was performed according to quality criteria of Western medicine (randomized, double-blind, placebo-controlled). The authors found that a Chinese herbal formula (Xiao Tan Jie Yu Fang) significantly improved PTSD related symptoms, i.e., improvement of somatization, obsessive-compulsive behavior, depression, anxiety, hostility and sleep quality.

Another well-known treatment modality of TCM is acupuncture, i.e., the needle-induced stimulation of energy channels in the body (meridians). Acupuncture is frequently used to relieve pain, but it can also be used to treat anxiety and depression [47]. More and more reports appear in the scientific literature that acupuncture successful reduces PTSD-related symptoms [48-50].

The strong philosophical background of TCM offers splendid opportunities for opening up dialogues with the humanities and for creating a transdisciplinary and multi-ontological framework of dealing with PTSD. Rather than the generation of theories in life sciences based on empirical inquiry and experimentation, TCM has its roots in diverse religious, social, philosophical and ethical systems, which have developed independently of TCM as medical system, but which have strongly influenced it. In this context, it has to be kept in mind that there is not one singular or monolithic TCM, but that TCM represents a heterogeneous conglomerate of different and partly even contrasting therapy practices [51]. Chinese philosophers developed theories, which redefined the basic assumptions of human life on earth. Rather than being dependent on supernatural powers in the form of spirits, demons and deities, they enfranchised human beings. The powers of life were described as $q i$ and blood-factors residing inside the human body. Hence, the human being has power over the spirits and not vice versa. Medicine is the tool to control the flow of spiritual energy in the body. Acupuncture is the method to correct and treat disturbances of the balanced flow of life energy between the organs along invisible energy vessels called meridians. This concept of medicine is based on the liberation of the human being from nature and spirits found in nature. By contrast, phytotherapy, as another major pillar of TCM is deeply rooted in naturalistic theories. Based on shamanistic practices, the Taoists thought that evil demons intended to harm human beings and that heavenly deities have to be convinced to prevent and heal diseases. Magical practices and the use of herbal mixtures are seen here as suitable means to win the fight against disease-bringing spirits [51].

These few sentences illustrate how tightly TCM is connected with ancient philosophical and religious beliefs. We suggest that we need to take advantage of this particular position of TCM and its location in-between philosophy on the one hand and medical practice and life sciences on the other. How could this be used as a nexus between life sciences and the humanities? This nexus becomes apparent, if one focuses on diagnostic methods commonly used in TCM. The TCM doctor tries to diagnose the diseases of patients by the following main methods: inspection of face and tongue, listening of the sound of voice and smelling, the odor of breath, inquiry of the disease history, as well as pulse diagnosis and palpation.

Whereas the patient inquiry about the disease most obviously resonates with narratives in the Western world, the stories a body can tell (e.g., color of face and tongue, weak voice, bad breathing odor, irregular pulse, etc.), stories which TCM can help us investigate, can also be understood as 
narrative alternatives: These stories told by the body provide interesting interfaces to the narratives investigated by literary research in Western academia. Because TCM is deeply rooted in the Chinese philosophy of human life, it is provides an ideal point of departure for approaches linking life sciences (here, the alternative life sciences model provided by TCM) and the humanities.

Even the handed-down TCM textbooks written by famous TCM scholars can be interpreted as narratives. In ancient times, many TCM doctors were under pressure to cure the diseases of their patients, and to record their success stories and favorite medications in books [51]. In this sense, these books constitute not only scientific textbooks, but also the life writing narratives of their authors.

As these descriptions demonstrate, there are a number of ways in which PTSD can be treated through TCM. So, how may we account for the fact that such treatment methods are usually absent from accounts of PTSD either in life science approaches or in documents of life writing? Within the life sciences, TCM has received less attention since treatment of PTSD has mostly focused on Western pharmacotherapy as well as talk therapy in the above mentioned framework. These established therapeutic forms can also be found in autobiographical and fictional accounts of patients suffering from PTSD. However, contrary to these approaches, our own reading seeks to recontextualize trauma narratives into a spectrum of alternative and complementary medical approaches, where alternative methods for treating PTSD are available, even if they are not widespread. Before applying this dialogic approach linking life sciences and life writing to the specific example of PTSD, it is necessary to identify core areas where such dialogues may seem particularly fruitful. These core areas are essential for interdisciplinary dialogues to occur especially since life writing spells out the existential dimension, the dimension of lived experience.

If, as approaches from the field of psychosomatic medicine make clear, traumas do not affect every individual the same way, documents or "data" from the field of life writing are essential in that they spell out precisely the individual dimension of lived experience. Even as patient narratives are of course an intrinsic part of, for instance, treatments in the field of talk therapy, specifically Narrative Exposure Therapy (NET), life writing narratives provide a larger framework (on the level of individual, collective, culturally and historically specific experience) in which these patient narratives may be inserted in order to gain a more comprehensive account of an individual patient's experience. Thus, in the US, a patient from an ethnic minority group may suffer from PTSD and may see a therapist focusing on NET. The latter's understanding of the patient's cultural background may be deepened, however, through an understanding of processes of cultural and collective victimization as they are conveyed in, for instance, ethnic autobiographies, fiction, blogs, or visual self-representation. It is at this juncture that life writing can in its turn influence treatment methods within life sciences which may ultimately change therapeutic strategies or at least create a more situated therapeutic setting for established treatment methods. The concept of "narrative" emerges as essential to the rethinking of traumatic experiences and other liminal experiences of human life.

In this context, however, a pressing question which has been widely overlooked or at least underestimated in the past is, whether psychological symptoms have their direct correlate in medical or molecular biological parameters. Is it heresy to ask the question, whether or not the success of psychotherapy might also depend on genetic predispositions? Thus, the above-mentioned focus on the cultural and social environment of the patient may not in itself be sufficient. Rather, a recent investigation found that single nucleotide polymorphisms in a gene associated with the glucocorticoid receptor (FKBP5, FK506-binding protein 51) was significantly related to the long-term effectiveness of narrative exposure therapy in 43 survivors of the rebel war in Northern Uganda [52]. This study represents another vivid example that crossing the borders between life sciences and life writing through interdisciplinary research may be a thriving and innovative topic. Moreover, to the extent that the humanities dismiss any relevance of genetic predispositions for the occurrence of PTSD, a dialogue with recent studies from the life sciences may cause them to reconsider this skepticism. 


\section{Theoretical Frameworks for Transdisciplinarity}

Since the beginning of the twentieth century, biomedical and life sciences have changed our life profoundly, and there are diverse cultural responses to this development, which has in itself been perceived as a constant boundary shift [53]. Against this background, the aims of our interdisciplinary research linking life sciences and life writing are to describe interfaces between Life Sciences and Life Writing by means of the concept of "narrativity" in order

- to develop a common way of speaking about liminal experiences of human life;

- to provide a systematic approach to experiences at the boundaries of human life allowing interpretation and dealing with shifting boundaries of life sciences and biomedicine; and

- to establish an informed exchange between life sciences and life writing, allowing for complementary interpretations of human life far beyond the borders of disciplinary thinking.

To achieve this goal, common approaches have to be established about the phenomenon of boundary experiences of human life. For this purpose, a focus on three levels of anthropological foundations of lived experience is suggested for the identification of boundary objects between life sciences and life writing.

- Corporeality: The reality and perception of one's own body.

- Capability: The set of capabilities needed for and present in all bio-psycho-social activities of life.

- Temporality: The phenomenological, objective and subjective structure and the course of time related to lived experience.

All three levels are deducible by biomedical explanations as well as by methods provided by humanities and cultural studies approaches for the interpretation of lived experience. Events representing existential fractures in life can be examined on the one hand by the textualizations of life narratives (autobiography, biography, diary, self-dramatization in film, video, on the internet) or, on the other hand, by the entire spectrum of biomedical interventions. The common goal is to achieve a convergence between the hitherto largely separate issues of cultural and natural sciences with the help of an improved understanding of narrative as a key concept of both natural sciences and the humanities.

The subject areas corporeality, capability and temporality do not only serve to facilitate access to experiences at the boundaries of human life, but they also to form a substantive link between disciplinary and methodologically different research fields. We will first discuss the usefulness of these concepts in developing interdisciplinary frameworks for research methodology and then go on to illustrate their application through PTSD as a specific example.

Corporeality: The body represents a "boundary concept" that reflects different epistemological conditions in relation to health and disease, in a general as well as a cross-cultural or gender-specific context. Moreover, the body can be understood as a site, where social expectations and cultural readings for the perception of human bodies meet. This perception can also be culturally conditioned. In the genre of Life Writing, therefore, basic assumptions of different medical cultures can be brought into view to illustrate possible ways of dealing with experiences at the boundaries of human life in different cultural contexts [54]. Corporeality can thus function as the missing link between life sciences and the humanities. If life writing research has often focused on the question of identity and the reshaping of identity in traumatic situations, it has also tended to neglect the corporeal dimensions of the trauma experience. For processes of healing, however, the notion of embodied experience is crucial.

At the same time, cultural studies and ecocritical approaches in the field of Life Writing assume that people are embedded in specific ecosystems, which are enriched by cultural value systems (such as the normativity of the concept of "naturalness") [5]. A critical understanding of the concept of the ecosystem both in a biological and in a cultural sense also implies ethical questions, if herbs might reveal side and toxicities on the one hand, but can be also used to alleviate the severe side effects of cytotoxic cancer chemotherapy on the other hand [55-59]. Such questions 
gain even more importance, if traditional medicine is the only available means for primary health care in rural areas of developing countries or if expensive medication for the treatment of infectious tropical diseases is not affordable for many poor people [60,61]. However, despite all social and economic contradictions on this globe, traditional and modern medicines should not be understood as mutually exclusive health care concepts. Rather, medicinal herbs and natural compounds are a valuable and indispensable source for pharmaceutical drug development across the globe [62]. Furthermore, herbal medicines can be subjected to the scientific principles of evidence-based medicine concerning determination of clinical effectiveness and molecular mode of action investigations as any other synthetic drug $[63,64]$. Thus, traditional medicine and Western life-sciences methodologies are by no means mutually exclusive.

Capabilities: Life can be understood as a narrative. A central topic to be explored in interdisciplinary research is the ability to understand the narrative dimensions of human life. However, the capability of telling a coherent story of one's life may be affected or destroyed by PTSD. An existential experience at the boundaries of human life may develop in a situation, where the experience cannot be told. The experience is located at the edge of narrativity; it leads to an aporia of textualization. This aporia-the "speechlessness" of the individual who has undergone a harrowing experience-can be psychologically occasioned (as, for instance, in PTSD) or it can be due to physical impairments (i.e., the loss of speech after a stroke). Traumatic experiences lead to posttraumatic states, where traumatized individuals are not capable of narrating their experience, neither regarding the content of this experience nor its spatially or temporally coherent form. This inability is reflected in neurobiological correlates (e.g., in the dopaminergic system) and it can be recognized by the occurrence of certain linguistic structures. Thus, a complementary view of traumatized patients may help improve therapeutic efforts in psychotherapy. This view can be provided by life writing research, because scholars trained in the method of interpreting life writing documents have explored particular forms of articulation (both verbal and non-verbal), they have been trained in analyzing and interpreting shifts in narrative perspective, and have researched the "reliability" of autobiographical narratives $[65,66]$.

In this context, it is interesting to investigate the loss of the narrative self, in which the individual can obtain access to the world only by the heteronomy of the disease. Narratives arising from this problem are characterized by striking differences between external description and self-perception, which, in extreme cases, may lead to the loss of the ability to narrate.

Temporality: Temporality can be identified as the third dimension, where life sciences and humanities need to collaborate to fully capture experiences at the boundaries of human life. Among these experiences, living with chronic illness is certainly the most challenging. It is one thing to narrowly escape one's impending death; it is quite another, however, to live with the perpetual possibility of one's dying, as in chronic illnesses. In order to fully capture the experience of living with—rather than living through—an illness, interdisciplinary reconceptualizations of temporality are indispensable. Unless medical interventions take into account the psychological effects of long-term therapy and the temporality involved in the experience of chronic illness, they will stop short of realizing the full potential of therapy.

Man sees himself not only as a biological being, but at the same time he is always a historical, biographical, intellectual, social, psychological, and spiritual being. We are always set under the terms of temporality asked, and-trivial as it may sound-under the condition of finiteness. Our finiteness means that our narrative never reflects our entire surrounding in "real time", but it can only provide snapshots and apertures. Against this background, temporality is as ubiquitous as it is existential as an experience of the edge of human life. The prospect of having a disease as a lifelong companion, necessarily leads to an adaptation of the individual to the requirements and challenges posed by the disease. This experience profoundly upsets our sense of temporality. It is here that it seems essential to provide the framework for a constructive dialogue between life sciences and life writing. Medical progress has made it possible, if not to cure diseases that used to be fatal, but to enable patients to live on, even if they have to be constantly monitored. What does it mean to live with 
a life-threatening disease? The most liminal experience of human life-the sense that one's own death is impending-is changed from an acute and sudden experience to an experience that is seemingly perpetual. What does it mean, in other words, to live with the sense of the finiteness of one's own life as it is brought about by chronic illness? It is here that the notion of "coping" falls short of conveying a form of complexity, which is far more nuanced. Medical research can help extend patients' lives, but it cannot address the consequences that this "prolongation" of the experience of illness at the boundaries of human life will have for the patient himself. It is here that life-writing research provides an important new field, which can be translated into both medical ethics and, to a different extent, into biomedical practice.

For instance, in diseases such as diabetes mellitus, the temporal development of strategies for dealing with the disease is not only an examination of the adaptation of the individual to the disease, but it is also a negotiation of an experience at the edge of human life. This negotiation is embedded into a discourse shaped by the private (individual), the public and the medical spheres, as examples taken from the field of the perception of cancer risks and the gender-specific individual response to this risk illustrate. Here, a critical dialogue between life writing research and cultural studies on the one hand and medical practice on the other hand is once again indispensable. Cultural studies research has investigated the public representation of certain diseases and their treatments in the course of history; this research may fruitfully converge with the medical-historical investigation of these diseases. Similarly, approaches in cultural and literary studies focus on the narrative dimension of the experience of illness, including the emotional level of this experience and the concepts resulting from it. In all these areas, the temporal dimension of individual or collective boundary experiences is apparent, e.g., in the experience of chronicity, in the individual's experiencing the reduction in life expectancy, or in the stretching and compression of the perception of time. It is these considerations that we will now go on to apply to the specific case of PTSD.

\section{PTSD as Example for Exploring Interdisciplinary Collaborations}

In the case of PTSD the experience of temporality is affected in a particular way, as the patient "relives" the traumatic experience time and again as if it were being located in the present, not the past. The condition of PTSD is thus the "condemnation" of the patient to have to relive the past in the present, and of having to relive the past over and over again. Through an interdisciplinary framework, PTSD can thus be described as confusion or "jumbling" of temporalities. This jumbling of temporalities, in turn, can be explored by scholars from the humanities and the life sciences in a joint reading of trauma narratives.

For the location from which we write, the need for such interdisciplinary frameworks is particularly acute. In the German media, discussions currently abound about the suffering of veterans returning from Afghanistan, many of them not only physically impaired, but also suffering from PTSD.

PTSD suddenly seems to have come "home" to Germany, and the challenge for German society will consist in developing ways of reintegrating these veterans into society and of helping them cope with their experiences. Unless society comes up with new approaches to "treating" (in more senses than one) PTSD, it may face a substantial crisis. It is here, we hope, that collaborative research between life sciences and life writing, may be especially useful [54]. Within the field of the humanities, there is also the need for a transnational dialogue. Whereas for the US, the reality of veterans living with PTSD has long been acknowledged, this reality has only recently been addressed in Germany. Because of the Vietnam War, as well as more recent military conflicts such as Desert Storm, US society has had to develop, on a massive scale, approaches to help veterans live "good lives". Moreover, recent approaches from the field of life writing provides us with a methodology to honor and to take seriously the voices of the veterans, and to develop ways in which to help them rewrite their biographies in a way in which, the jumbled temporality brought about by PTSD notwithstanding, they will once again be able to live lives they find fulfilling. 
The stories of German Afghanistan veterans point to the necessity of exploring the overlaps between trauma and life writing [67-69]. Significantly, life writing narratives stress the experience of Afghanistan as a rupture or juncture in these veterans' biographies. What all their narratives agree on is that after Afghanistan, life cannot go on as before. A new kind of temporality has to be found. This new temporality can only be achieved through a radical break with the past, the time before the soldiers went to Afghanistan. We believe that research on autobiographies-told as oral narratives, in writing, or in blogs—as a form of life writing provides an important starting point through which, in a collaboration between life writing and life sciences, therapy of PTSD can occur. To be sure, not all Afghanistan veterans suffer from PTSD, but as their biographies and autobiographical accounts indicate, they have all been affected by traumatic experiences to varying degrees. These traumatic experiences have been exacerbated by a denial of these experiences by the German public.

Since the intervention of German troops in Afghanistan as part of a peace-keeping mission has itself been highly controversial for the German public, the voices and narratives of returning soldiers have often been silenced due to this political climate. Future research between life writing and the life sciences will thus have to square two important tasks. First, it will have to collect these narratives of German veterans from Afghanistan in multiple forms: In oral narratives, in written accounts such as blogs or websites, in court testimonies, in media coverage, and, at the final end of the spectrum, also in fictional accounts such the crime novel in Brennende Kälte by Schorlau [69]. The proliferation of fictional accounts of Afghanistan veterans in crime novels or in feature films indicate that this is an issue, which concerns the zeitgeist of the German public. These fictional accounts, however, need to be "verified" and reconsidered by linking them to life writings by actual war veterans returning from Afghanistan. Moreover, there is clearly a global dimension to life writing about veterans' traumata. Thus, the French writer Olivier Morel, living in the US, has recently produced a film which captures the experience of American soldiers returning from war and suffering from PTSD [70]. There is hence a continuity between fictional accounts such as Morel's and Schorlau's, on the one hand and, on the other hand, life writing narratives about veterans affected by PTSD as they currently proliferate in German media. These accounts, dealing with veterans returning from Afghanistan and other combat zones, many of them suffering from PTSD, will pose new challenges to the humanities and to the life sciences. Treating PTDS, through both therapy and medication, will be impossible without also taking into account the stories which these veterans have to tell, the ways in which they choose to write or tell their experiences, or the extent to which they have become unable to speak about these experiences. To restore to these veterans the capability of narrative, is one of the challenges for interdisciplinary research linking life sciences and life writing.

First, these narratives need to be inserted into a corpus of narratives by patients suffering from PTSD. Second, they need to be read through medical diagnoses (including those from psychosomatic medicine and alternative and complementary medical approaches). Third, they can also be read through theoretical concepts emerging from life writing research, concepts which would enable us to comprehend more fully the dimension of narrative, the experience of having to relive the traumatic event and of being deprived of linear logic and narrative coherence, and the consequences this has for the identity of a PTSD patient.

A key lacuna, which can be located in accounts of Afghanistan war veterans is the absence of a recourse to treatment methods by alternative and complementary medicine. TCM is now also available in Germany, even as there is clearly a need for standardization and close monitoring of practitioner's medical credentials. One area which needs to be much more closely researched is the possibility of treating patients suffering from PTSD, including Afghanistan war veterans, through TCM. If such treatment were made widely available, the narratives which these veterans are able to tell may in time come to be different, as treatment methods would no longer be limited to talk therapy by and large in the mode of Narrative Exposure Therapy (NET) and Western pharmacotherapy. Such alternative treatment methods, in turn, may eventually give rise to new narratives in the field 
of life writing, narratives in which new forms of overcoming PTSD and of living fuller lives after returning from war are suddenly made possible.

\section{Conclusions}

In this paper, we have tried to point to the necessity for developing interdisciplinary methodologies linking the life sciences and the field of life writing, as it has become central to current humanities research. We have suggested that further research is necessary in two fields. First, interdisciplinary methodologies have to be described on the level of theory and of developing hypotheses. Second, these hypotheses then have to be verified by being brought to bear on actual case studies. These case studies, we have suggested, can also be located in life writing narratives and in autobiographical accounts, for instance, by German war veterans returning from Afghanistan. From this vantage point, we have argued, developing interdisciplinary frameworks between life sciences and life writing is not only an academic endeavor, it may also be a social necessity.

Acknowledgments: This research has been funded by the Deutsche Forschungsgemeinschaft, grant 2015/1 (GRK"Life Science-Life Writing").

Author Contributions: Norbert W. Paul designed the project and edited the paper. Mita Banerjee wrote the passages concerning life writing research. Thomas Efferth wrote and edited the paper.

Conflicts of Interest: The authors declare no conflict of interest.

\section{Abbreviations}

5-HTTLPR dopamine receptor, serotonin transporter

APA American Psychiatric Association

COMT catechole-O-methyl transferase

CpG cytosine pphosphate guanine DNA sequence motif

DNA deoxyribonucleic acid

DSM Diagnostic and Statistical Manual of Mental Disorders

EMDR eye movement desensitization and reprocessing

FKBP5 FK506 binding protein 5

GABA gamma-aminobutyric acid

GC glucocorticoid

H19 imprinted maternally expressed transcript (non-protein coding DNA sequence)

HPA hormonal hypothalamic-pituitary-adrenal axis

IL18 interleukin 18

LHPA limbic-hypothalamic-pituitary-adrenal axis

LINE-1 long interspersed nuclear element 1

NET narrative exposure therapy

NR3C1 nuclear receptor subfamily 3, group C, member 1 (glucocorticoid receptor)

NR3C2 nuclear receptor subfamily 3, group C, member 2PE, prolonged exposure therapy

PTSD posttraumatic stress syndrome

SEP Socioeconomic position

SNP single nucleotide polymorphism

STS Science and Technology Studies

TCM traditional Chinese medicine

\section{References}

1. Hamilton Nolan. "PTSD and Me: True Stories from Military Veterans." Gawker, 19 August 2013. Available online: http:/ /gawker.com/ptsd-and-me-true-stories-from-military-veterans-1167107848 (accessed on 28 December 2015). 
2. Elizabeth S. Cohen. "Court Testimony from the Past: Self and Culture in the Making of Text." In Essays on Life Writing: From Genre to Critical Practice. Edited by Marlene Kadar. Toronto: University of Toronto Press, 1992; pp. 83-93.

3. Marlene Kadar. "From Genre to Critical Practice." In Essays on Life Writing. Edited by Marlene Kadar. Toronto: University of Toronto Press, 1992; pp. 3-16.

4. Marijke Huisman. “Introduction: Life Writing Matters in Europe.” In Life Writing Matters in Europe. Edited by Marijke Huisman, Anneke Ribberink, Monica Soeting, and Alfred Hornung. Heidelberg: Winter, 2012; pp. 9-21.

5. Alfred Hornung, and Baisheng Zhao. Ecology and Life Writing. Heidelberg: Winter, 2013.

6. Mita Banerjee. Color Me White: Naturalism/Naturalization in American Literature. Heidelberg: Winter, 2013.

7. Norbert W. Paul, Mita Banerjee, and Susanne Michl. "Captious certainties: Makings, meanings and misreadings of consumer-oriented genetic testing." Journal of Community Genetics 5 (2014): 81-87. [CrossRef] [PubMed]

8. Kay Schaffer, and Sidonie Smith. Human Rights and Narrated Lives: The Ethics of Recognition. New York: Palgrave, 2004.

9. Nicola Waller, and Carl Eduard Scheidt. "Narration as a means of restoring self-coherency: Thoughts on processing traumatic experiences." Zeitschrift Fuer Psychosomatische Medizin und Psychotherapie 56 (2010): 56-73. [CrossRef] [PubMed]

10. Jonathan I. Bisson, Neil P. Roberts, Martin Andrew, Rosalind Cooper, and Catrin Lewis. "Psychological therapies for chronic post-traumatic stress disorder (PTSD) in adults." Cochrane Database System Review 12 (2013): CD003388.

11. Ulrich Schnyder, Anke Ehlers, Thomas Elbert, Edna B. Foa, Berthold P. R. Gersons, Patricia A. Resick, Francine Shapiro, and Marylène Cloitre. "Psychotherapies for PTSD: What do they have in common?" European Journal of Psychotraumatology 6 (2015): 28186. [CrossRef] [PubMed]

12. Edna B. Foa, Terence M. Keane, Matthew J. Friedman, and Judith A. Cohen. "Effective Treatments for PTSD." In Practise Guidelines from the International Society for Traumatic Stress Studies. New York: Guilford Press, 2009.

13. Ellen M. Volpe, Camille R. Quinn, Kathryn Resch, Marilyn S. Sommers, Elizabeth Wieling, and Catherine Cerulli. "Narrative Exposure Therapy: A Proposed Model to Address Intimate Partner Violence-Related PTSD in Parenting and Pregnant Adolescents." Family E Community Health, 2015: forthcoming.

14. Katherine C. Hughes, and Lisa M. Shin. "Functional neuroimaging studies of post-traumatic stress disorder." Expert Review of Neurotherapeutics 11 (2011): 275-85. [CrossRef] [PubMed]

15. Timmy Jones, and Mary D. Moller. "Implications of Hypothalamic-Pituitary-Adrenal Axis Functioning in Posttraumatic Stress Disorder." Journal of the American Psychiatric Nurses Association 17 (2011): 393-403. [CrossRef] [PubMed]

16. Inger Johansson, and Magnus Ingelman-Sundberg. “Genetic Polymorphism and Toxicology—With Emphasis on Cytochrome P450." Toxicological Sciences 120 (2011): 1-13. [CrossRef] [PubMed]

17. Farooq Kiani, Sonja Schwarzl, Stefan Fischer, and Thomas Efferth. "Three-Dimensional Modeling of Glucose-6-Phosphate Dehydrogenase-Deficient Variants from German Ancestry." PLoS ONE 2 (2007): e625. [CrossRef] [PubMed]

18. Ella T. Nkhoma, Charles Poole, Vani Vannappagari, Susan A. Hall, and Ernest Beutler. "The global prevalence of glucose-6-phosphate dehydrogenase deficiency: A systematic review and meta-analysis." Blood Cells, Molecules and Diseases 42 (2009): 267-78. [CrossRef] [PubMed]

19. Julia DiGangi, Guia Guffanti, Katie A. McLaughlin, and Karestan C. Koenen. "Considering trauma exposure in the context of genetics studies of posttraumatic stress disorder: A systematic review." Biology of Mood $\mathcal{E}$ Anxiety Disorders 3 (2013): 2. [CrossRef] [PubMed]

20. Florence Gressier, Raffaella Calati, Martina Balestri, Agnese Marsano, Siegfried Alberti, Niki Antypa, and Alessandro Seretti. “The 5-HTTLPR Polymorphism and Posttraumatic Stress Disorder: A Meta-Analysis." Journal of Traumatic Stress 26 (2013): 645-53. [CrossRef] [PubMed]

21. Ulrike Ehlert. "Enduring psychobiological effects of childhood adversity." Psychoneuroendocrinology 38 (2013): 1850-57. [CrossRef] [PubMed]

22. Carina Rampp, Elisabeth B. Binder, and Nadine Provençal. "Epigenetics in posttraumatic stress disorder." Progress in Molecular Biology and Translational Science 128 (2014): 29-50. [PubMed] 
23. Ali B. Rodgers, and Tracy L. Bale. "Germ Cell Origins of Posttraumatic Stress Disorder Risk: The Transgenerational Impact of Parental Stress Experience." Biological Psychiatry 78 (2015): 307-14. [CrossRef] [PubMed]

24. Adrian M. Stankiewicz, Artur H. Swiergiel, and Pawel Lisowski. "Epigenetics of stress adaptations in the brain." Brain Research Bulletin 98 (2013): 76-92. [CrossRef] [PubMed]

25. Stefanie Malan-Müller, Soraya Seedat, and Sian M. Hemmings. “Understanding posttraumatic stress disorder: Insights from the methylome." Genes Brain Behavior 13 (2014): 52-68. [CrossRef] [PubMed]

26. Nikolaos P. Daskalakis, Rosemary C. Bagot, Karen J. Parker, Christiaan H. Vinkers, and E. Ronald de Kloet. "The three-hit concept of vulnerability and resilience: Toward understanding adaptation to early-life adversity outcome." Psychoneuroendocrinology 38 (2013): 1858-73. [CrossRef] [PubMed]

27. Janine L. Kwapis, and Marcelo A. Wood. “Epigenetic mechanisms in fear conditioning: Implications for treating post-traumatic stress disorder." Trends Neuroscience 37 (2014): 706-20. [CrossRef] [PubMed]

28. Rachel Yehuda, Janine D. Flory, Linda M. Bierer, Clare Henn-Haase, Amy Lehrner, Frank Desarnaud, Iouri Makotkine, Nikolaos P. Daskalakis, Charles R. Marmar, and Michael J. Meaney. "Lower methylation of glucocorticoid receptor gene promoter $1 \mathrm{~F}$ in peripheral blood of veterans with posttraumatic stress disorder." Biological Psychiatry 77 (2015): 356-64. [CrossRef] [PubMed]

29. Rachel Yehuda, Nikolaos P. Daskalakis, Frank Desarnaud, Iouri Makotkine, Amy L. Lehrner, Erin Koch, Janine D. Flory, Joseph D. Buxbaum, Michael J. Meaney, and Linda M. Bierer. “Epigenetic Biomarkers as Predictors and Correlates of Symptom Improvement Following Psychotherapy in Combat Veterans with PTSD." Frontiers Psychiatry 4 (2013): 118. [CrossRef] [PubMed]

30. Yvonne Bockmühl, Alexandre V. Patchev, Arleta Madejska, Anke Hoffmann, Joao C. Sousa, Nuno Sousa, Florian Holsboer, Osborne F. Almeida, and Dietmar Spengler. "Methylation at the CpG island shore region upregulates Nr3c1 promoter activity after early-life stress." Epigenetics 10 (2015): 247-57. [CrossRef] [PubMed]

31. Glenn E. Schafe. “Epigenetics: A new frontier for post-traumatic stress disorder?" Epigenomics 6 (2014): 157-59. [CrossRef] [PubMed]

32. Daniel S. Schechter, Dominik A. Moser, Ariane Paoloni-Giacobino, Ludwig Stenz, Marianne Gex-Fabry, Tatjana Aue, Wafae Adouan, Marea I. Cordero, Francesca Suardi, Aurelia Manini, and et al. “Methylation of NR3C1 is related to maternal PTSD, parenting stress and maternal medial prefrontal cortical activity in response to child separation among mothers with histories of violence exposure." Frontiers in Psychology 6 (2015): 690. [CrossRef] [PubMed]

33. Rachel Yehuda, Nikolaos P. Daskalakis, Linda M. Bierer, Heather N. Bader, Torsten Klengel, Florian Holsboer, and Elisabeth B. Binder. "Holocaust Exposure Induced Intergenerational Effects on FKBP5 Methylation." Biological Psychiatry. Published electronically 12 August 2015. [CrossRef] [PubMed]

34. Jennifer A. Rusiecki, Celia Byrne, Zygmunt Galdzicki, Vasantha Srikantan, Ligong Chen, Matthew Poulin, Liying Yan, and Andrea Baccarelli. "PTSD and DNA Methylation in Select Immune Function Gene Promoter Regions: A Repeated Measures Case-Control Study of U.S. Military Service Members." Frontiers Psychiatry 4 (2013): 56. [CrossRef] [PubMed]

35. Jennifer A. Rusiecki, Ligong Chen, Vasantha Srikantan, Lei Zhang, Liying Yan, Matthew L. Polin, and Andrea Baccarelli. "DNA methylation in repetitive elements and post-traumatic stress disorder: A case-control study of US military service members." Epigenomics 4 (2012): 29-40. [CrossRef] [PubMed]

36. Satoshi Toyokawa, Monica Uddin, Karestan C. Koenen, and Sandro Galea. "How does the social environment 'get into the mind'? Epigenetics at the intersection of social and psychiatric epidemiology." Social Science $\mathcal{E}$ Medicine 74 (2012): 67-74. [CrossRef] [PubMed]

37. Monica Uddin, Sandro Galea, Shun Chiao Chang, Karestan C. Koenen, Emily Goldmann, Derek E. Wildman, and Allison E. Aiello. "Epigenetic signatures may explain the relationship between socioeconomic position and risk of mental illness: Preliminary findings from an urban community-based sample." Biodemography and Social Biology 59 (2013): 68-84. [CrossRef] [PubMed]

38. Levent Sipahi, Monica Uddin, Zhou-Cheng Hou, Allison E. Aiello, Karestan C. Koenen, Sandro Galea, and Derek E. Wildman. "Ancient evolutionary origins of epigenetic regulation associated with posttraumatic stress disorder." Frontiers in Human Neuroscience 8 (2014): 284. [CrossRef] [PubMed]

39. Linda Mabey, and Gwen van Servellen. "Treatment of post-traumatic stress disorder in patients with severe mental illness: A review." International Journal of Mental Health Nursing 23 (2014): 42-50. [CrossRef] [PubMed] 
40. Jonathan C. Ipser, and Dan J. Stein. "Evidence-based pharmacotherapy of post-traumatic stress disorder (PTSD)." International Journal of Neuropsychopharmacology 15 (2012): 825-40. [CrossRef] [PubMed]

41. Matthew Jeffreys, Bruce Capehart, and Matthew J. Friedman. "Pharmacotherapy for posttraumatic stress disorder: Review with clinical applications." Journal of Rehabilitation Research \& Development 49 (2012): 703-15. [CrossRef]

42. Kathleen A. Head, and Gregory S. Kelly. "Nutrients and Botanicals for Treatment of Stress: Adrenal Fatigue, Neurotransmitter Imbalance, Anxiety, and Restless Sleep." Alternative Medicine Review 14 (2009): 114-40. [PubMed]

43. Jerome Sarris, and David J. Kavanagh. “Kava and St. John's Wort: Current Evidence for Use in Mood and Anxiety Disorders." Journal of Alternative and Complementary Medicine 15 (2009): 827-36. [CrossRef] [PubMed]

44. Sui-yu Hu, Su-e Wang, and Chun-hu Zhang. "Relationship between symptom stratification and syndrome differentiation of traditional Chinese medicine for depressive episode." Zhong Xi Yi Jie He Xue Bao 9 (2011): 933-36. [CrossRef] [PubMed]

45. Nityamo Sinclair-Lian, Michael Hollifield, Margaret Menache, Teddy Warner, Jenna Viscaya, and Richard Hammerschlag. "Developing a Traditional Chinese Medicine Diagnostic Structure for Post-Traumatic Stress Disorder." Journal of Alternative and Complementary Medicine 12 (2006): 45-57. [CrossRef] [PubMed]

46. Xian-Ze Meng, Feng Wu, Pin-Kang Wei, Li-Juan Xiu, Jun Shi, Bin Pang, Da-Zhi Sun, Zhi-Feng Qin, Yi Huang, and Lixing Lao. "A Chinese Herbal Formula to Improve General Psychological Status in Posttraumatic Stress Disorder: A Randomized Placebo-Controlled Trial on Sichuan Earthquake Survivors." Evidence-Based Complementary and Alternative Medicine 2012 (2012): 691258. [CrossRef] [PubMed]

47. Ying Zhang, Bin Feng, Jian-ping Xie, Fang-zhong $\mathrm{Xu}$, and Jiong Chen. "Clinical Study on Treatment of the Earthquake-Caused Post-Traumatic Stress Disorder by Cognitive-Behavior Therapy and Acupoint Stimulation." Journal of Traditional Chinese Medicine 31 (2011): 60-63. [CrossRef]

48. Marisa Pease, Richard Sollom, and Peter Wayne. "Acupuncture for Refugees with Posttraumatic Stress Disorder: Initial Experiences Establishing a Community Clinic." Explore (NY) 5 (2009): 51-54. [CrossRef] [PubMed]

49. Michael Hollifield, Nityamo Sinclair-Lian, Teddy D. Warner, and Richard Hammerschlag. "Acupuncture for Posttraumatic Stress Disorder: A Randomized Controlled Pilot Trial." The Journal of Nervous and Mental Disease 195 (2007): 504-13. [CrossRef] [PubMed]

50. Michael Hollifield. “Acupuncture for Posttraumatic Stress Disorder: Conceptual, Clinical, and Biological Data Support Further Research." CNS Neuroscience Therapeutics 17 (2011): 769-79. [CrossRef] [PubMed]

51. Paul U. Unschuld. Traditionelle Chinesische Medizin. München: Beck CH Wissen, 2013.

52. Sarah Wilker, Anett Pfeiffer, Stephan Kolassa, Thomas Elbert, Birke Lingenfelder, Emilio Ovuga, Andreas Papassotiropoulos, Dominique de Quervain, and Iris-Tatjana Kolassa. "The role of FKBP5 genotype in moderating long-term effectiveness of exposure-based psychotherapy for posttraumatic stress disorder." Translational Psychiatry 4 (2014): e403. [CrossRef] [PubMed]

53. Paul Rabinow. Anthropos Today: Reflections on Modern Equipment. Princeton: Princeton University Press, 2003.

54. Thomas Efferth, Mita Banerjee, and Alfred Hornung. "Therapeutic Intervention of Post-traumatic Stress Disorder by Chinese Medicine: Perspectives for Transdisciplinary Cooperation between Life Sciences and Humanities." Medicine Studies 4 (2014): 71-89. [CrossRef]

55. Mahmoud Youns, Jörd D. Hoheisel, and Thomas Efferth. "Toxicogenomics for the Prediction of Toxicity Related to Herbs from Traditional Chinese Medicine." Planta Medica 76 (2010): 2019-25. [CrossRef] [PubMed]

56. Thomas Efferth, and Bernd Kaina. "Toxicities by Herbal Medicines with Emphasis to Traditional Chinese Medicine." Current Drug Metabolism 12 (2011): 989-96. [CrossRef] [PubMed]

57. Moustapha Ouedraogo, Thomas Baudoux, Caroline Stevigny, Joëlle Nortier, Jean-Marie Colet, Thomas Efferth, Fan Qu, Jue Zhou, Kelvin Chan, Debbie Shaw, and et al. "Review of current and 'omics' methods for assessing the toxicity (genotoxicity, teratogenicity and nephrotoxicity) of herbal medicines and mushrooms." Journal of Ethnopharmacology 140 (2012): 492-512. [CrossRef] [PubMed]

58. Troy Allard, Thomas Wenner, Henry Johannes Greten, and Thomas Efferth. "Mechanisms of Herb-Induced Nephrotoxicity." Current Medicinal Chemistry 20 (2013): 2812-19. [CrossRef] [PubMed] 
59. Gesa Meyer-Hamme, Kathrin Beckmann, Janine Radtke, Thomas Efferth, Henry Johannes Greten, Matthias Rostock, and Sven Schröder. "A Survey of Chinese Medicinal Herbal Treatment for Chemotherapy-Induced Oral Mucositis." Evidence-Based Complementary and Alternative Medicine 2013 (2013): 284959. [CrossRef] [PubMed]

60. Tilman Polonio, and Thomas Efferth. "Leishmaniasis: Drug resistance and natural products (Review)." International Journal of Molecular Medicine 22 (2008): 277-86. [CrossRef] [PubMed]

61. Simon Turschner, and Thomas Efferth. "Drug resistance in Plasmodium: Natural products in the fight against malaria." Mini Reviews in Medicinal Chemistry 9 (2009): 206-14. [CrossRef] [PubMed]

62. David Newman, and Gordon M. Cragg. "Natural Products as Sources of New Drugs over the 30 Years from 1981 to 2010." Journal of Natural Products 75 (2012): 311-35. [CrossRef] [PubMed]

63. Thomas Efferth. "Personalized Cancer Medicine: From Molecular Diagnostics to Targeted Therapy with Natural Products." Planta Medica 76 (2010): 1143-54. [CrossRef] [PubMed]

64. Thomas Efferth. "Stem Cells, Cancer Stem-Like Cells, and Natural Products." Planta Medica 78 (2012): $935-42$. [CrossRef] [PubMed]

65. Stefan Martini, and Andreas von Arnauld. "Unreliable Narration in Law Courts." In Unreliable Narration and Trustworthiness: Intermedial and Interdisciplinary Perspectives. Edited by Vera Nünning, and Ansgar Nünning. Berlin: De Gruyter, 2015. published as Vera Nünning. "Unreliable narration und die historische Variabilität von Werten und Normen: The Vicar of Wakefield als Testfall für eine kulturgeschichtliche Erzählforschung." In Narration: Studien zur Theorie und Praxis Unglaubwürdigen Erzählens in der Englischsprachigen Erzählliteratur. Edited by Ansgar Nünning. Trier: Wissenschaftsverlag Trier, 1998, pp. 257-85.

66. Johannes Clair. Vier Tage im November. Mein Kampfeinsatz in Afghanistan. Berlin: Econ, 2012.

67. Robert Sedlatzek-Müller. Soldatenglück: Mein Leben Nach Dem Überleben. Hamburg: Edel Verlag, 2012.

68. Sabine Würich, and Ulrike Scheffer. Operation Heimkehr: Bundeswehrsoldaten Über ihr Leben Nach Dem Auslandseinsatz. Berlin: Ch. Links Verlag, 2014.

69. Wolfgang Schorlau. Brennende Kälte. Frankfurt: KiWi, 2008.

70. Olivier Morel. On the Bridge. Paris: Arte France, 2011.

(C) 2015 by the authors; licensee MDPI, Basel, Switzerland. This article is an open access article distributed under the terms and conditions of the Creative Commons by Attribution (CC-BY) license (http://creativecommons.org/licenses/by/4.0/). 